\title{
MANUFACTURING TECHNOLOGY OF SOME IMPACT RESISTANT MATERIALS
}

\author{
Iulian PĂDURARU, Vasile BRIA, Adrian CÎRCIUMARU \\ "Dunarea de Jos" University of Galati, Romania \\ e-mail: iulian.paduraru@ugal.ro
}

\begin{abstract}
In this paper impact resistance is a key parameter for composite materials. Composite structures can experience impact loads either accidentally in the designed life or in an anticipated hostile service environment. That is why the manufacturing technology is very important. For materials manufacture were established: the type of polymer matrix, the types of fabrics and additives which will be used to improve impact resistance and also analysis of mechanical properties of formed composite materials (bending and tensile tests). Knowledge of the mechanical properties of polymeric materials is necessary in all areas of their applicability. Thus, rigidity and mechanical strength are key properties for most applications in which polymeric matrix composites are used.
\end{abstract}

KEYWORDS: impact resistance, epiphen, composite materials

\section{Introduction}

A composite material consists of two elements: the support matrix for the second component, the reinforcement and/or the additive chosen depending on the field of use of the composite material formed and the properties it is intended to have [1]. The properties of the composite depend on the properties of the constituents, the ratios of their presence in the final material, the shapes and dimensions of the dispersed phase or phases [2]. Engineers are often required to provide impact energy data for various components. Impact resistance is the ability of a material to withstand a sudden applied load and is expressed in terms of energy. The impact involves the collision of two bodies: the impactor and the target. In a collision, the contact force develops as the impactor pushes the target [3]. Knowledge of the dynamic response of the structure and its resistance to damage is very necessary to optimize the structure that requires high safety, such as structural applications of aircraft. Under laboratory-controlled conditions, impact testing can be used to validate prototype models or to ensure that they meet the durability and safety requirements of the products.

In the last 15 years, a large number of new highperformance polymer fibres have been developed, including aramid fibers (Kevlar $\AA$, Twaron $®$ ), polyethylene fibers (Dyneema®, Specter $\AA$ ) and polypropylene fibers (Curv®), Tegris $\left.{ }^{\circledR}\right)$ [4].
Many analytical models that predict the impact resistance of composite materials are available. Among the authors who have contributed in this field we list Shivakumar [5], Christoforou [6, 7], Olsson [8] and, more recently, Talagani [9]. The methods they use include energy balance models to predict maximum force [10], simple models that determine the response over time, and more complex models that involve series extensions.

Low energy impact tests can be defined as events that can occur in the range of $1-50 \mathrm{~m} / \mathrm{s}$ depending on the rigidity of the target, the properties of the materials, the mass and the rigidity of the projectile. A low-speed impact can occur during operation or during maintenance and can be considered one of the most dangerous [11].

Currently, no acceptable standard test procedures are available for testing the impact of composites. As a result, a wide variety of test procedures, test tube geometries and data analysis techniques are currently used. Gas guns offer representative approaches for assessing the impact response of composite materials. That is why the analysis of mechanical properties of formed composite materials (bending and tensile tests) provides precursor data for impact tests.

For the formation of materials were established: the type of polymer matrix, the types of fabrics and additives, which will be used in order to improve impact resistance, analysis of mechanical properties of composite materials (bending and tensile tests). 


\section{Materials and methods}

The following fabrics were chosen for the formation of materials: glass fabric with a density of
$280 \mathrm{~g} / \mathrm{m}^{2}$, carbon fabric with a specific density of 240 $\mathrm{g} / \mathrm{m}^{2}$, low-density carbon-Kevlar fabric and highdensity carbon-Kevlar fabric.

Table 1. Characteristics of carbon fabric with specific density $240 \mathrm{~g} / \mathrm{m}^{2}$

\begin{tabular}{|cccc}
\hline Characteristics & Nominal & Tolerance & Normative \\
\hline Mass per unit area $\left[\mathrm{g} / \mathrm{m}^{2}\right]$ & 240 & $\pm 5 \%$ & ISO 4605 \\
\hline Fabric & simple & & ISO 2113 \\
Thickness [mm] & 0.20 & $\pm 2.5 \%$ & ISO 5084
\end{tabular}

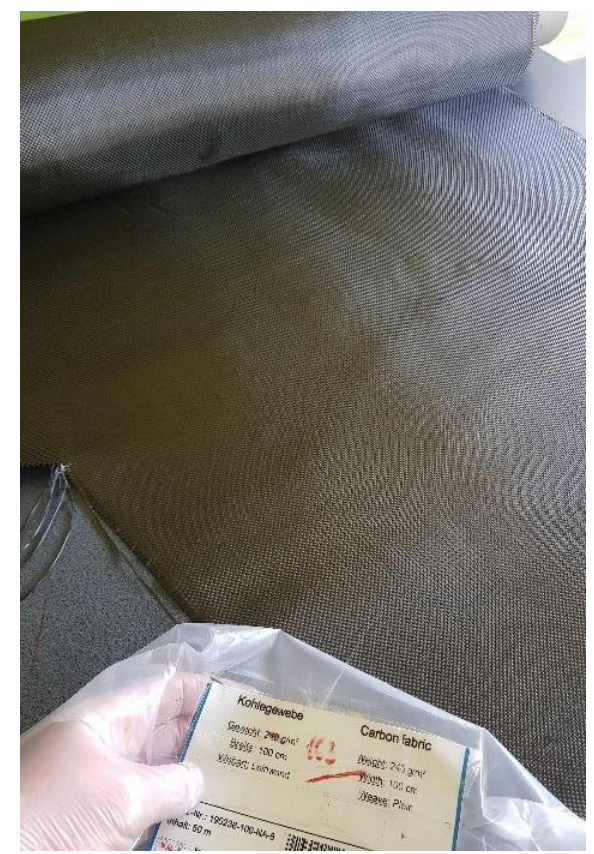

Fig. 1. Carbon fabric with a specific density of $240 \mathrm{~g} / \mathrm{m}^{2}$

Table 2. Properties of carbon fabric with specific density $240 \mathrm{~g} / \mathrm{m}^{2}$

\begin{tabular}{ccc} 
Nominal construction & Warp & Wefit \\
\hline Description of fibers & HR Carbon Fiber $3 \mathrm{~K}-200$ tex & HR Carbon Fiber $3 \mathrm{~K}-200$ tex \\
Number of threads & $6.0 \mathrm{knots} / \mathrm{cm}-$ ISO 4602 & $6.0 \mathrm{knots} / \mathrm{cm}-\mathrm{ISO} 4602$ \\
Weight distribution & $120 \mathrm{~g} / \mathrm{m}^{2}$ & $120 \mathrm{~g} / \mathrm{m}^{2}$ \\
Weight rate & $50 \%$ & $50 \%$
\end{tabular}

Glass fabric has mechanical properties approximately comparable to that of carbon. Although not as strong or rigid as carbon fibre, it is much cheaper and significantly less brittle when used in composites. Therefore, glass fibre is used as a curing material for many polymeric products. A solvent was used to treat the glass fabric, which was sprayed onto the fabric and can be seen in the figure below. The drying of the fabric was done in a wellventilated space.
After treating the fabrics, the architectures of the composite materials were established. Sheets were cut from fabrics with dimensions $210 \times 297 \mathrm{~mm}$ and the orientation of the fibres at $0^{\circ},-30^{\circ}, 30^{\circ}, 45^{\circ}, 60^{\circ}$ and $90^{\circ}$ depending on the configuration of the layers.

The components of the epoxy system used in this study are: EPYPHEN RE resin with EPIPHEN DE 4020 hardener with short curing time. Clays have high elasticity, high compressibility, high swelling capacity, in-permeability and dimensional stability. 


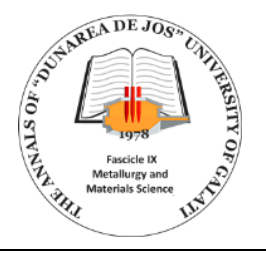

THE ANNALS OF "DUNAREA DE JOS” UNIVERSITY OF GALATI

FASCICLE IX. METALLURGY AND MATERIALS SCIENCE

No. 1 - 2021, ISSN 2668-4748; e-ISSN 2668-4756

Article DOI: $\underline{\text { https://doi.org/10.35219/mms.2021.1.08 }}$

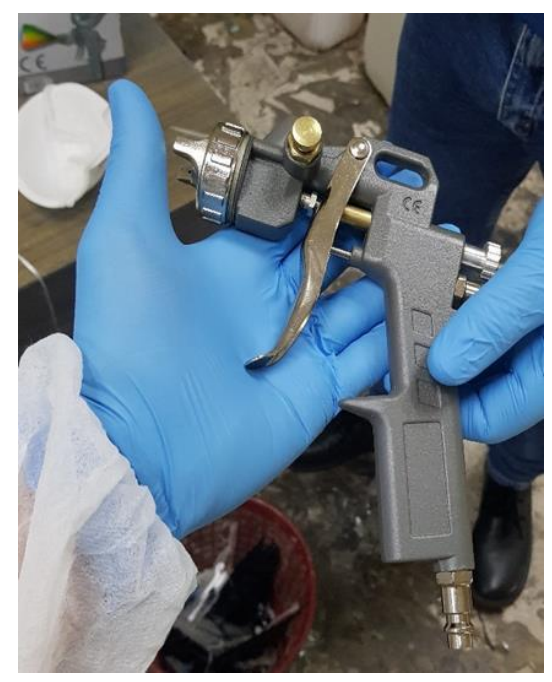

Fig. 2. Sprayer device used to treat glass fibre

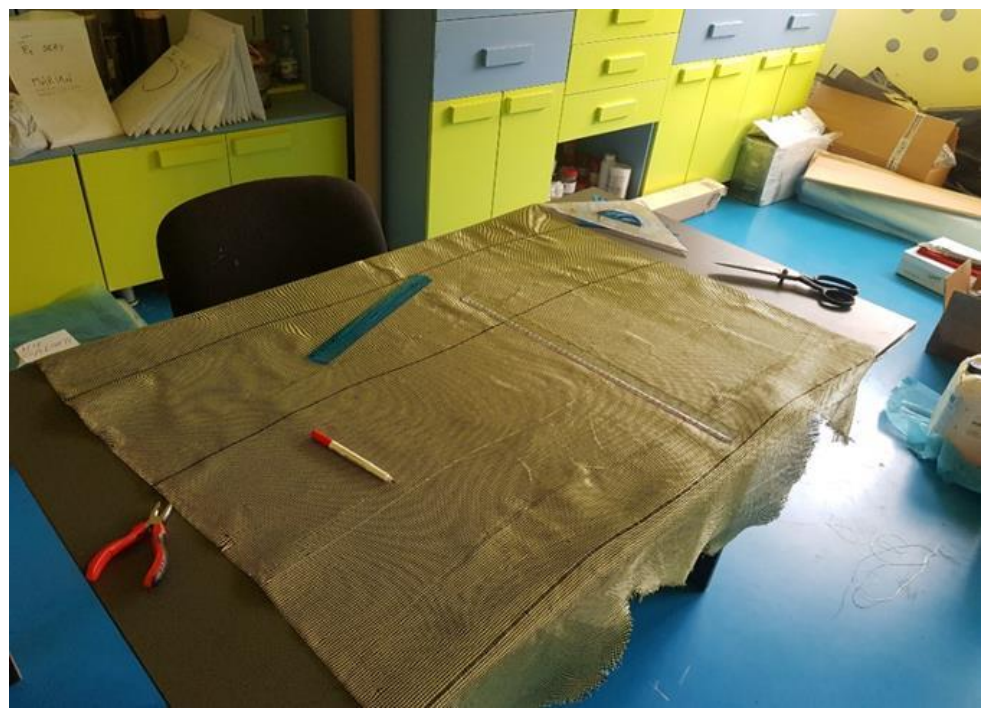

Fig. 3. Cutting high-density carbon-Kevlar fabric at different sizes

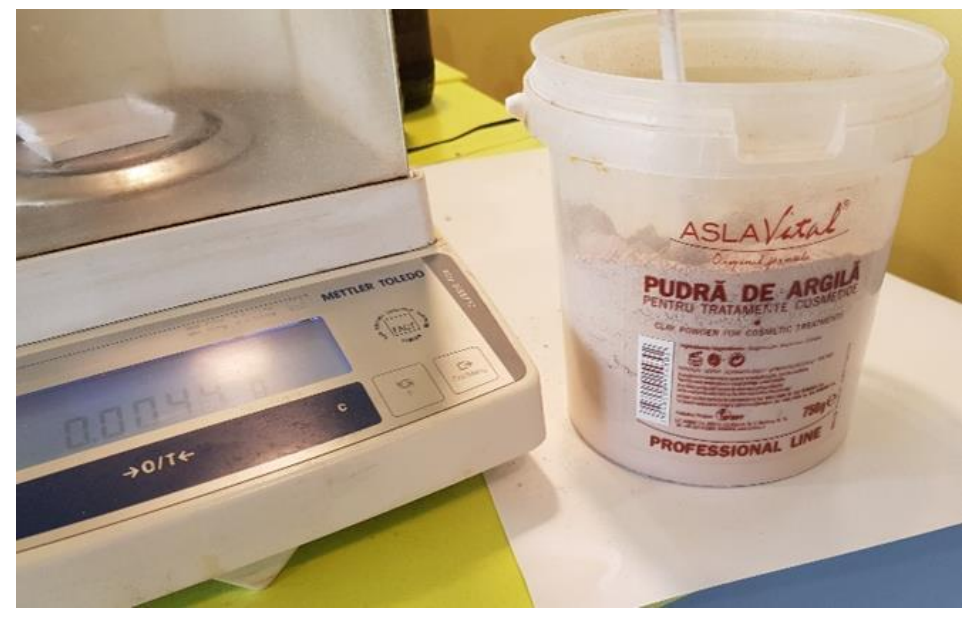

Fig. 4. Clay powder used in the manufacture of composite materials 


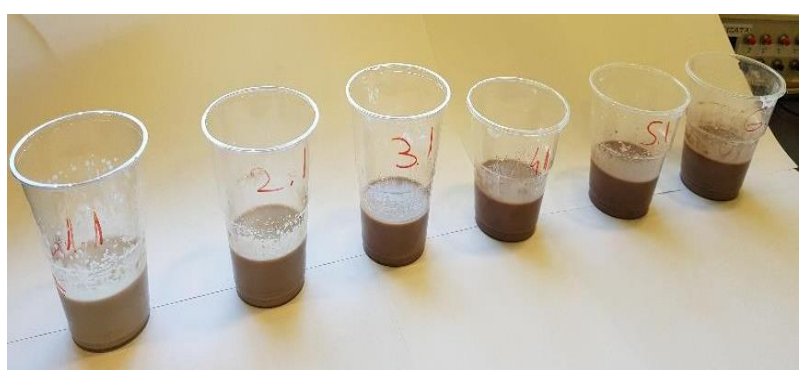

Fig. 5. Volume percentages of clay in epoxy resin

Table 3. Calculation of the quantities of materials used in the formation of composite materials

\begin{tabular}{|c|c|c|c|c|c|}
\hline & $\begin{array}{c}\text { Mixture } \\
{[\mathbf{g}]}\end{array}$ & $\begin{array}{c}\text { EPIPHEN } \\
\text { RE 4020 }[\mathbf{g}]\end{array}$ & $\begin{array}{c}\text { EPIPHEN } \\
\text { DE 4020 }[\mathbf{g}]\end{array}$ & $\begin{array}{c}\text { Clay } \\
{[\mathbf{g}]}\end{array}$ & $\begin{array}{c}\text { Total } \\
{[\mathbf{g}]}\end{array}$ \\
\hline $\mathrm{A} 17+1 \%$ & 40 & 40 & 12 & 0.92 & 92 \\
\hline $\mathrm{A} 9+2 \%$ & 28.42 & 47.36 & 14.2 & 1.83 & 90 \\
\hline $\mathrm{A} 1+3 \%$ & 12 & 60 & 18 & 2.78 & 90 \\
\hline $\mathrm{A} 1+4 \%$ & 12 & 60 & 18 & 3.75 & 90 \\
\hline $\mathrm{A} 1+5 \%$ & 12 & 60 & 18 & 4.73 & 90 \\
\hline $\mathrm{A} 1+6 \%$ & 12 & 60 & 18 & 5.74 & 90 \\
\hline
\end{tabular}

Two glass plates measuring $210 \times 297 \mathrm{~mm}$ were used to form the materials. For more efficient removal of polymer composites from the mould, polypropylene foils were used between the glass plates and the material (epoxy resin does not adhere to their surface). They were arranged in the matrix layer by layer by soaking and embedding them directly in the matrix. After the introduction of all layers, the mould was closed and placed in a horizontal position to ensure the quality of the structure and surfaces of the formed materials.

\section{Results}

Composite materials consist of 30 layers of fabric as follows:

- the first 10 layers of low-density carbonKevlar fabric;

- the next 5 layers of high-density carbon-Kevlar fabric;

- the next 10 layers of glass cloth with a density of $280 \mathrm{~g} / \mathrm{m}^{2}$;

- the following 5 layers of carbon fabric with a specific density of $240 \mathrm{~g} / \mathrm{m}^{2}$.

Table 4. Orientation of the layers in the composite material

\begin{tabular}{|c|c|c|c|}
\hline No. layer & Orientation & No. layer & Orientation \\
\hline 1 & $0^{\circ}$ & 16 & $0^{\circ}$ \\
\hline 2 & $30^{\circ}$ & 17 & $-60^{\circ}$ \\
\hline 3 & $45^{\circ}$ & 18 & $45^{\circ}$ \\
\hline 4 & $-30^{\circ}$ & 19 & $30^{\circ}$ \\
\hline 5 & $0^{\circ}$ & 20 & $90^{\circ}$ \\
\hline 6 & $0^{\circ}$ & 21 & $-90^{\circ}$ \\
\hline 7 & $30^{\circ}$ & 22 & $30^{\circ}$ \\
\hline 8 & $45^{\circ}$ & 23 & $45^{\circ}$ \\
\hline 9 & $-30^{\circ}$ & 24 & $60^{\circ}$ \\
\hline 10 & $0^{\circ}$ & 25 & $0^{\circ}$ \\
\hline 11 & $0^{\circ}$ & 26 & $30^{\circ}$ \\
\hline 12 & $30^{\circ}$ & 27 & $45^{\circ}$ \\
\hline 13 & $45^{\circ}$ & 28 & $-30^{\circ}$ \\
\hline 14 & $-30^{\circ}$ & 29 & $0^{\circ}$ \\
\hline 15 & $0^{\circ}$ & 30 & \\
\hline
\end{tabular}



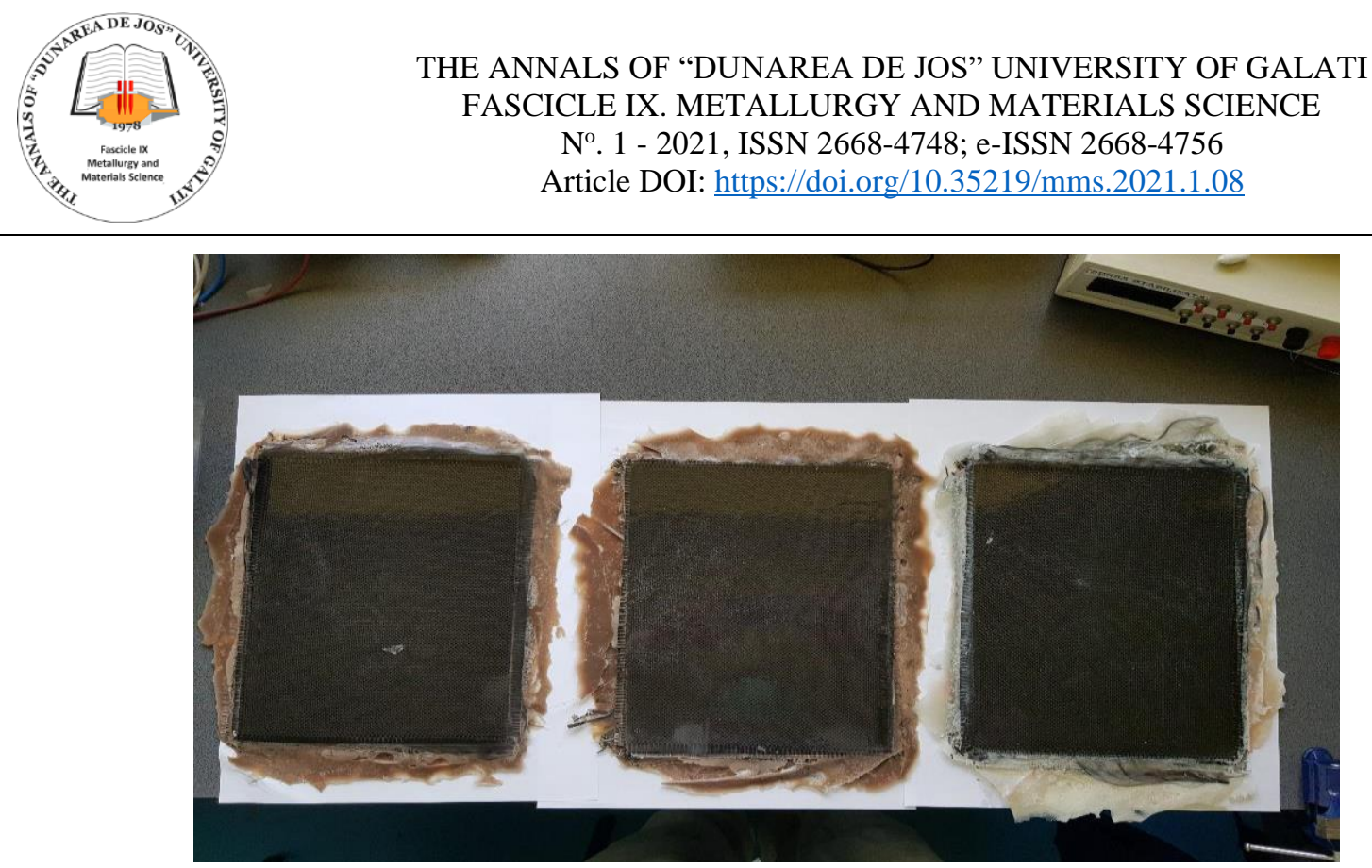

Fig. 6. Formed composite materials

\section{Conclusions}

Preparation methods of a polymeric composite material involves several steps: the amount of material required. This was determined by calculating the volume of mixture required. So, the polymeric matrix is established. This implies the polymerization time, the formation temperature and the properties of the formed materials. Another step is the choice or fixation of the modifier (modifying agent), which provides its choice to improve the properties of the material depending on its size and behaviour. The behavior of materials during mechanical stresses (produced by external forces) depends on the specific characteristics of the material from which the parts are formed.

\section{References}

[1]. Alămoreanu E., Mihai Constantinescu D., Proiectarea plăcilor compozite laminate, Editura Academiei Române, București, 2005.
[2]. Callister W. D., Materials Science and Engineering, John Wiley \& Sons, 1994.

[3]. Gin B. C., Periyasamy M., Low velocity impact response of fibre-metal laminates - A review, Composite Structures 107, p. 363-381, 2014.

[4]. Iannucci L., Pope D., High velocity impact and armour design, XPRESS Polymer Letters, vol. 5, no. 3, p. 262-272, 2011.

[5]. Shivakumar K. N., Elber W., Illg W., Prediction of impact force and duration due to low-velocity impact on circular composite laminates, Journal of Applied Mechanics, 52(3), p. 674680, September 1985.

[6]. Christoforou A. P., Swanson S. R., Analysis of impact response in composite plates, International Journal of Solids and Structures, 27(2), p. 161-170, 1991.

[7]. Christoforou A. P., Yigit A. S., Characterization of impact in composite plates, Composite Structures, 43, p. 14-24, 1998.

[8]. Olsson R., Mass criterion for wave controlled impact response of composite plates, Composites Part A: Applied Science and Manufacturing, 31(8), p. 879-887, August 2000.

[9]. Talagani M. R., Impact analysis of composite structures. PhD thesis, Delft University of Technology, December 2014.

[10]. Esrail F., Kassapoglou C., An efficient approach for damage quantification in quasiisotropic composite laminates under low speed impact, Composites Part B: Engineering, 61, p. 116-126, May 2014.

[11]. Shivakumar K. N., Elber W., Illg W., Prediction of low velocity impact damage in thin circular laminates, American Institute of Aeronautics and Astronautics Journal, p. 442-449. 1985. 